\title{
LA DEVOCIÓN A SAN JORGE DURANTE EL SIGLO XVIII EN DURANGO. A PROPÓSITO DE UN LIENZO CONSERVADO EN LA SACRISTÍA DE LA CATEDRAL
}

\author{
DEVOTION TO SAINT GEORGE DURING THE XVIIITH CENTURY \\ IN DURANGO. ON A CANVAS PRESERVED IN THE SACRISTY \\ OF THE CATHEDRAL
}

\section{Adolfo Martínez Romero UNAM - México}

ABSTRACT • St. George was one of the best known figures in Christendom, due both to his unique story as well as for the help he gave to the various Spanish kingdoms in the fight against the enemies of Jesus Christ. His cult spread to New Spain where he was known, although not in the same manner as in Europe. But nevertheless, in the cathedral of the bishopric of Durango, the efforts of bishop Pedro Anselmo Sánchez de Tagle interests resulted in St. George being declared patron of the city in 1749 by both civil and ecclesiastical chapters. This event granted the saint another function: the fight against poisonous animals, specifically, the scorpions endemic to the region. As a result, the Saint's iconography experienced an unprecedented and meaningful change that included the depiction of a series of arachnids alongside the dragon. This is reflected in the canvas that is still located in the sacristy of this cathedral, a painting that is unique in the History of Art.

KEYWORDS: Saint George; Iconography; Bishop; Nobiliary Shield; Scorpions; Devotion; Sacristy.

RESUMEN • San Jorge fue una de las figuras más difundidas en todo el Cristianismo, tanto por su singular historia como por el auxilio que prestó a los diversos reinos españoles en la lucha contra los enemigos de Jesucristo. Su culto logró llegar a la Nueva España donde fue conocido, aunque no siempre con el mismo sentido. Así, en la Catedral del Obispado de Durango, los intereses del obispo Pedro Anselmo Sánchez de Tagle lograron que el Cabildo Civil y el Cabildo Eclesiástico juraran a este santo como patrono de la ciudad en 1749. Este hecho le asignó una nueva encomienda: la lucha contra los animales ponzoñosos, específicamente los alacranes. Igualmente, este evento inédito permitió que a través de los años, la visualidad habitual de san Jorge haya experimentado uno de los cambios más significativos, al incluir una serie de arácnidos junto a la famosa representación del dragón. Lo anterior se ve reflejado en el gran lienzo que se conserva en la sacristía de dicha catedral, el cual es único dentro de la Historia del Arte.

PALABRAS CLAVES: San Jorge; Iconografía; Obispo; Escudo nobiliario; Alacranes; Devoción; Sacristía. 
La figura del soldado de Capadocia tiene su origen desde épocas muy tempranas en el mundo oriental. Durante el medievo, su presencia se extendió por toda la Cristiandad en Occidente, al grado de ser reconocida en toda Europa. Esto permitió que el santo se convirtiera en patrono de diversas regiones. Así lo evidencian algunos estudios de gran interés, entre ellos, El patró sant Jordi. Historia, llegenda, art (Sayrach, 1996) y El señor san Jorge. Patrón de Aragón (Montaner, 1999). Además, este personaje es considerado uno de los santos caballeros armados que protegieron diversos intereses políticos y religiosos de los gobernantes de aquellos tiempos. Por ejemplo, en España, su figura tiene un lugar especial dentro de la historia debido a que fue el protector de victoriosas batallas que libraron algunos reinos en contra de los enemigos de la fe cristiana. Empero, no fue el único. Así como san Jorge fue estandarte para las milicias de Aragón (Linares, 2011: 2), especialmente cuando Pedro I conquistó a los moros en el año de 1096 en la batalla de Alcoraz, el apóstol Santiago lo fue para las Coronas de León y Castilla. Ambos santos guerreros llevaron a sus reyes a los más grandiosos triunfos militares contra sus enemigos. Por supuesto, entre estos dos caballeros existió una rivalidad, por lo menos en la retórica de la época que atendía constantemente a sus propios intereses. Por ejemplo, fray Manuel de Espinoza en 1799 señalaba que san Jorge:

ha sido una devoción extraordinariamente popular, embellecida continuamente por los fieles de innumerables países, vinculada a leyendas de gran fuerza épica y poética, auxilio permanente de los guerreros defensores de Roma y el pontificado y que, en España, granó únicamente en los Estados de la Corona de Aragón por la formidable competencia que se generó en la Corona de Castilla en torno nada menos que a Santiago (Espinoza, 1799).

De acuerdo a la revisión que realizó Enrique Olivares sobre la tradición de estos santos caballeros, se puede decir que finalmente el patronazgo de Santiago de Compostela logró vencer como patrón de las Españas hacia el siglo XV con la unión de Castilla y Aragón.

Las representaciones de los santos guerreros forman parte de un programa iconográfico que constantemente se utilizó para sacralizar la guerra que, según Tomás Madalena (1721) «en la iglesia primitiva no se pedía en la misa por la paz, pero repitiéndose las persecuciones de la iglesia, se introdujo por ceremonia» (p. 182). Así, estas guerras fueron encausadas contra los enemigos de la Iglesia y de Dios. Es decir, herejes, idólatras, paganos y los moros, quienes eran equiparados con el mismo demonio, lo cual justificaba este tipo de batallas. No se puede dejar de lado que el caballo es un elemento esencial e importante que distingue a estos santos. González Estévez menciona que la representación de este animal tiene su origen desde la era paleocristiana, mismo que se constituyó como «un soporte iconográfico de la santidad» (p. 177).

A diferencia del resto de los santos guerreros, san Jorge lucha contra un dragón que, dentro de la iconografía cristiana ha sido el símbolo perfecto para representar el mal en todo su esplendor (Olivares, 2015: 294). Sin embargo, el santo de Capadocia ha sido cuestionado constantemente, tanto por su lucha contra esta bestia, como por la ausencia de una hagiografía fidedigna. Por ejemplo, Federico Borromeo (1624) en su libro De pictura sacra mencionaba que «la famosa lotta sostenuta da San Giorgio contro il Demonio non è parimenti attestata da prove sicure, benchè non vogliamo punto negare che quel santo sia stato caro e accetto a Dio» (Cap. XI). Después, en el siglo XVII el canónigo de la iglesia de Sevilla y caballero de la orden de Santiago, Nicolás Antonio, en varios escritos que dejo sin terminar y que fueron publicados en 1742 por Gregorio Mayans y Siscar, trató de buscar la racionalidad ante tales historias. Antonio menciona que su texto es «en efecto, una censura de historias, i no de qualquiera, 
sino de historias Fabulosas, que con sus ficciones, mentiras, i embustes, han falseado las memorias de toda la antigüedad, representando en ella poblaciones, personas, i acciones, que nuca hubo". Específicamente, sobre san Jorge menciona que "tan ilustre en su fama, como obscuro en las circunstancias de su vida, i martirio, hicieron los Hereges antiguos las suertes que pudieron, llenando su relación de fabulas, i otras cosas, que cedia, mas en desprecio, i irrision del martir, que en edificación de los fieles» (p. 330).

A pesar de las disidencias pasadas y de lo que significó en épocas recientes el dictamen negativo sobre la existencia de san Jorge durante el Concilio Vaticano II (1965), su figura y su fama han estado presentes, tanto en el viejo continente que lo venera con fervorosas procesiones, como en algunas regiones de América.

\section{SAN JORGE EN AMÉRICA}

Tras la conquista de América por parte de los españoles en el siglo XVI, una innumerable lista de santos y devociones cruzaron el océano Atlántico y se arraigaron en las diferentes poblaciones. San Jorge también lo hizo, aunque acompañado de otros santos guerreros como el glorioso san Miguel y Santiago Matamoros, los cuales tuvieron un protagonismo mayor y una difusión notable en la Nueva España que dejó casi en la total invisibilidad al santo de Capadocia. Recuérdese que Santiago fue quien se apareció en múltiples ocasiones durante la conquista, tal y como lo señala Francisco López de Gomara en su Historia de la conquista de México. Al Respecto, Báez (1979) menciona que:

entre Santiago de Compostela y san Miguel hay una obvia diferencia de rango, pues si el apóstol fue patrón y protector de los tercios españoles, san Miguel lo fue de toda la cristiandad, y si el primero hubo de intervenir para apoyar la conquista, el segundo fue necesario para exterminar los últimos restos de cultos prehispánicos, afirmando en cambio un catolicismo militante y triunfante (p. 29).

A raíz de dicha importancia, en toda América existen numerosas poblaciones bautizadas con el nombre de Santiago y san Miguel, mas no así con el nombre de san Jorge, a excepción de dos que se encuentran en la actual Sudamérica. La primera se trata de aquella población que fundó fray Pedro de Betanzos entre 1550 y 1560 dentro del reino de Guatemala (hoy dentro de la actual Nicaragua). La leyenda indica que el nombre de San Jorge de Rivas, como hoy se conoce, se le dio después de que el santo se apareció un 23 de abril de 1777. Cabe destacar que en este lugar se estableció un convento bajo la advocación de este santo. La segunda fundación es la de San Jorge del Cartago que ocurrió el 9 de agosto de 1540 (hoy municipio de Cartago, en Colombia), la cual estuvo a cargo del mariscal Jorge Robledo, proveniente de Santiago de Cali, quien tuvo como objetivo consolidar la expansión española en esas provincias. Empero, en estos dos casos no hay un sólo indicio para afirmar que la figura del santo fue utilizada como estandarte de una empresa militar, como así sucedió en los territorios del viejo continente. Ni siquiera, el título del marqués de San Jorge, concedido en 1777 a José Miguel Lozano de Peralta en Bogotá, tiene alguna connotación militar.

En México tampoco existen numerosos poblados o ciudades bajo el nombre de san Jorge. A la fecha, sólo se conoce el caso de una pequeña ranchería llamada San Jorge, hoy actual poblado de San Pedro del Rosal, municipio de Atlacomulco, en el Estado de México. 
Lo interesante es que en esta población aún existe una pequeña capilla dedicada a este santo. Por otro lado, dentro de la catedral de Chilapa, en el estado de Guerrero, se venera a san Jorge junto a la figura de san Miguel. Por último, la catedral de Durango es el sitio con mayor devoción hacia el soldado de Capadocia. Aunque la presencia del santo en el México actual es limitada, los actos de devoción que se llevan a cabo en su honor son ilustrativos. Por supuesto, no se comparan con aquellas que se llevan a cabo con gran fervor en España, como en Palos de la Frontera, en Huelva o en Alcoi. Respecto a las esculturas utilizadas en las celebraciones mexicanas, sólo la de Durango es de la época virreinal y su patronazgo se diferencia de las demás debido a que tiene la función de dar protección a los habitantes contra los alacranes. Esta pequeña relación de fundaciones poblacionales, comparada con las que se hicieron en honor a Santiago y san Miguel, permite dimensionar la importancia de la figura de san Jorge en la Nueva España. Por lo anterior, se puede entender por qué los estudios académicos sobre este santo son mínimos. Casi nulos. Hay dos razones muy concretas: la primera tiene que ver con la falta significativa de documentación histórica; y la segunda, con la poca presencia de piezas, tanto escultóricas como pictóricas, dentro de las colecciones novohispanas, lo que impide realizar un estudio iconográfico como el que se ha hecho durante décadas en Europa.

Como consecuencia del primer punto, la historiografía novohispana que se ha encargado de develar muchos aspectos devocionales de la sociedad de acuerdo a sus intereses y su identificación con diversos santos (Gomar, 1993: 4-9), no ha podido hacer mucho respecto al caso de san Jorge. La ausencia de noticias en las diferentes publicaciones mexicanas confirma que su culto fue limitado. Por ejemplo, tanto la Gaceta de México de Castorena y Ursua que circuló durante el siglo XVIII, como el Diario de México que se publicó durante el siglo XIX, sólo se limitan a señalar en sus santorales que el 23 de abril se celebraba a este santo. Sin embargo, no hacen referencia a ningún tipo de celebración especial en ninguna de las regiones del virreinato. Las únicas devociones que sobresalen son aquellas de la Virgen de los Remedios y la Virgen de Guadalupe, las cuales eran requeridas para pedir auxilio por las inundaciones, sequías y hambrunas que aquejaban a los pobladores, sobre todo durante el siglo XVIII. Por lo anterior, se debe entender que las diversas expresiones religiosas dentro de la Nueva España fueron distintas en cada región. Es decir, los norteños novohispanos no asimilaron lo mismo que los habitantes de las regiones del centro y sur. Ni las devociones fueron las mismas ni su entrega a estas creencias. Tal es el caso de san Jorge que se juró patrono de Durango en 1749 y no en algún otro lugar.

Por otro lado, la falta de piezas de este santo dentro de los recintos religiosos novohispanos también refleja que su culto fue bastante disminuido. A la fecha sólo se han localizado unas cuantas. Lamentablemente, de todas ellas no se pudieron obtener los permisos necesarios para su reproducción en esta investigación. Por ejemplo, dentro de la colección del Museo Franz Mayer, en la Ciudad de México, se encuentra un textil español del siglo XVII que representa a san Jorge matando al dragón.

En cuanto a obras pictóricas, se conoce aquella que parece representar a san Jorge, como así lo sugirió Edelmira Ramírez. ${ }^{1}$ La pintura forma parte de un expediente localizado en el Archivo General de la Nación. Se trata de una denuncia que hizo ante el Tribunal de la Inquisición el mulato y esclavo Juan Manuel contra Martin Alonso en 1643, quien era pintor de unos cuarenta años y originario de Zitlalá (cerca del actual municipio de Chilapa, en Guerrero). El reclamo en su contra fue por haber representado una figura demoniaca. En

1. <https://www.azc.uam.mx/publicaciones/tye/representaciondesanjorge.htm> 
dicho expediente se lee que, Nicolás Ponce le había pedido al pintor Alonso hacer un dibujo con «un hombre a caballo, con una lanza en la mano y unas alas en el pecho; y en lugar de cola, una culebra, y le mandó que esta figura de este animal tuviese las uñas muy grandes».2 El pintor se negó a realizarlo por andar ocupado en el convento del pueblo. Sin embargo, tras la insistencia de Ponce, al final accedió y lo realizó «de la misma forma y modo que se le pidió. Y que las alas que puso en el caballo, que era para que si corriera por algunos malos pasos volara y no cayera; y que la culebra que le mando poner en el lugar de la cola, que no le dijo el efecto para qué era" ${ }^{3}$ Por esta pintura recibió un pago de un real.

El 22 de julio de 1643, el pintor Alonso fue citado por las autoridades de Chilapa para que volviera a realizar el dibujo como se lo había pedido Nicolás Ponce, lo cual cumplió sin reservas. Cuatro días después, el Tribunal mostró el dibujo al mulato Juan Manuel, quien negó que ese haya sido el retrato que le vio por primera vez en manos de Ponce. Según su testimonio, el original se trataba de «un hombre de a pie, horrible y espantoso, con unos cuernos grandes, y una cola grande como cola de culebra, con unas uñas grandes en los pies, y las manos como uñas de gallo». ${ }^{4}$ Tan grande fue el susto que a este mulato, según su declaración «le temblaron las carnes». ${ }^{5}$ Debido a que el expediente está incompleto, es imposible saber la resolución del caso. El dibujo entregado al Tribunal parece más una representación de san Jorge, esto si se atiende a la presencia del caballo, el dragón y la armadura y la lanza que lleva el hombre [fig. 1]. Es muy posible que el pintor hubiera recurrido a la temática de este santo para no ser sentenciado.

Las librerías corales son otros repositorios novohispanos que también dan testimonio de la utilización visual de san Jorge. Por ejemplo, en uno de los libros de la Catedral metropolitana de la Ciudad de México se puede apreciar una pequeña iluminación hecha a mediados del siglo XVIII, muy cercana a la representación tradicional de este santo. Por otro lado, en la colección de libros de coro de la Catedral de Durango hay un ejemplar muy singular hecho hacia 1774, el cual contiene el oficio de Jacobo apóstol. En la iluminación principal se observa al santo con armadura, montado a caballo y matando a un moro con su lanza. Dentro de este mismo oficio hay una pequeña representación de un alacrán. He aquí la singularidad de este ejemplo. Recuérdese que san Jorge fue jurado en Durango hacia 1749 para luchar contra estos animales. Esto sugiere que la inclusión de este arácnido en la sección correspondiente al apóstol fue con la idea de que también Santiago, como santo guerrero, pudiera dar auxilio a la población contra estos alacranes. Si así lo hacía san Jorge, ¿por qué no lo haría el apóstol? Los responsables de este hecho fueron José Remigio Puelles de Uresti, primer sochantre de la catedral, quien puso en metro los diez oficios y dos himnos que contiene dicho libro y Nicolás Zepeda, quien hizo las iluminaciones. Sin duda, el referente iconográfico para que estos dos maestros hayan incluido este arácnido en el oficio del apóstol Santiago fue el lienzo de san Jorge que hoy se encuentra en la sacristía de la catedral, el cual fue hecho hacia 1760 - 70, mismo que incluye una serie de animales ponzoñosos. Los motivos de esta manipulación se expondrán más adelante por ser el objetivo principal de este trabajo.

2. Archivo General de la Nación, Inquisición, vol. 416, expediente 15, 1643, fojas: 252 - 256. En adelante AGN. Cabe destacar que Edelmira Ramírez en su texto señala erróneamente que el expediente referido se encuentra en el volumen 4 del ramo Inquisición. Sin embargo, realmente se encuentra en el volumen 416.

3. AGN, Inquisición, volumen 416, expediente 15, 1643

4. AGN, Inquisición, volumen 416, expediente 15, 1643.

5. AGN, Inquisición, volumen 416, expediente 15, 1643.

IMAGO, NÚM. 10, 2018, 125-142 




Fig. 1. Martin Alonso, San Jorge, óleo sobre papel, año 1643. 
Cristóbal de Villalpando (1649 - 1714), quien fue un pintor de los más afamados y prolíficos de la Nueva España, es autor de una obra titulada Jesús en el aposentillo, la cual fue parte de un retablo que estuvo en el templo jesuita de San Pedro y San Pablo en la Ciudad de México hacia 1696 (Gutiérrez, 1997: 290). En esta pintura se aprecia la aparición de animales como cucarachas, ratas y otras sabandijas como lagartijas, culebras y algunos alacranes. Curiosamente, los animales que pintó Villalpando denotan cierto desconocimiento de su complexión. Así, lo ejemplifica la cabeza de la culebra y el cuerpo del alacrán. Esta imagen puede verse en el catálogo de la obra de este pintor (Gutiérrez, 1997).

Por otro lado, la existencia de trabajos escultóricos del santo es casi nula. Sólo la colección Behrens (dispersa actualmente) posee una pieza muy temprana: una escultura de caña de maíz del siglo XVI dorada con un tenue estofado, la cual está registrada como san Jorge. Lamentablemente, esta pieza ya no está acompañada de sus atributos más significativos como son el dragón, la lanza y la espada, por lo que se dificulta asegurar su reconocimiento como este santo.

Finalmente, la catedral de Durango cuenta con dos esculturas muy interesantes: una se localiza dentro de su capilla y otra en uno de los nichos del segundo cuerpo de la portada exterior lateral poniente de dicha catedral. La primera es de madera y muestra al santo montado en su caballo como se venía haciendo desde las primeras representaciones [fig. 2]. Su rostro es imberbe y casi infantil. El estofado que se puede observar es mínimo, lo que indica el gusto por las nuevas técnicas escultóricas de mediados del siglo XVIII. La pieza fue comprada en la Ciudad de México en 1749, expresamente para colocarla en su capilla, la cual estaba en construcción durante este año. La segunda pieza de san Jorge es de talla en cantera y fue realizada por Pedro de Huertas hacia 1780, como parte del adorno de la portada lateral de la catedral. El modelo de esta pieza se puede hallar en aquella escultura que realizó Donatello para el gremio de los armeros (Iglesia del Huerto de san Miguel, 1417). Empero, no deben olvidarse otras piezas magníficas europeas de san Jorge, como aquella obra que hizo

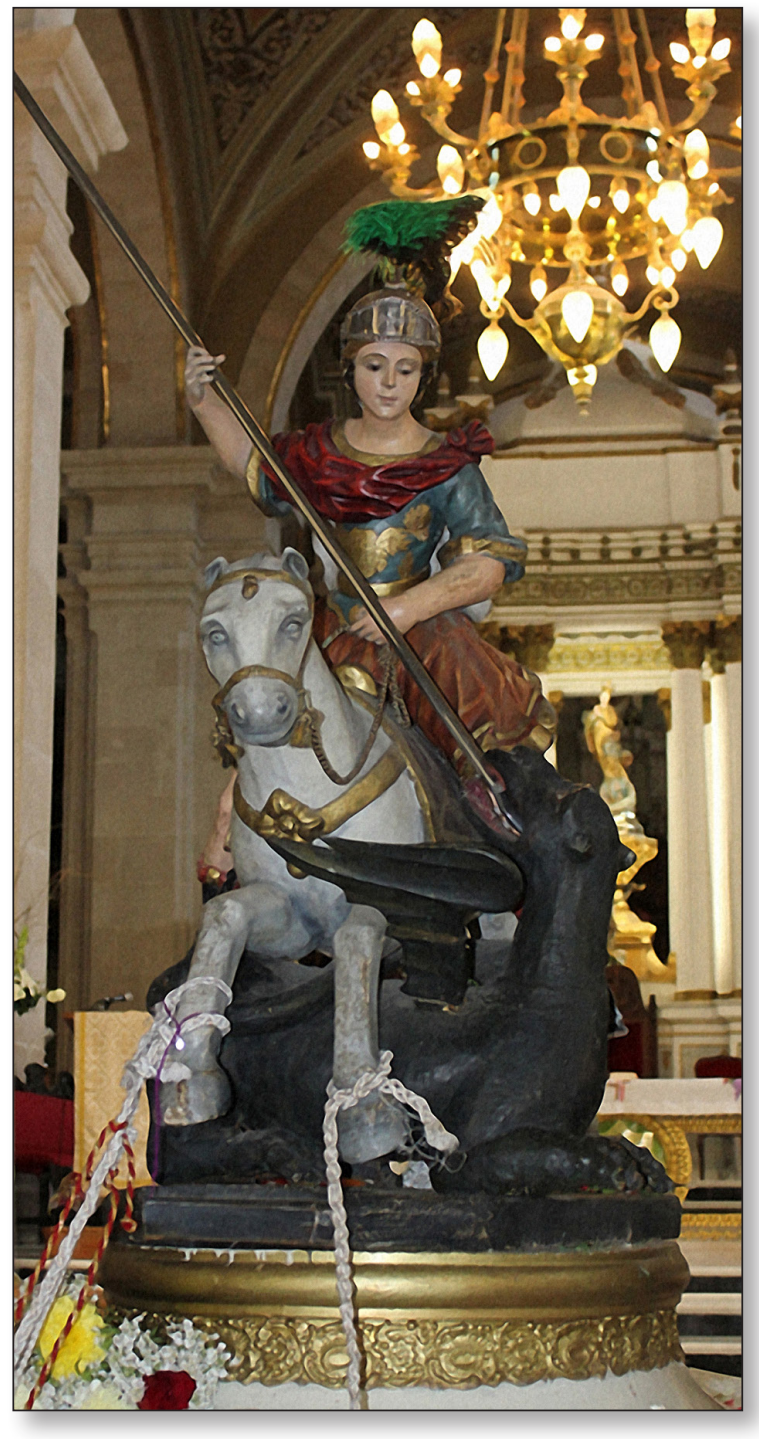

Fig. 2. Anónimo, San Jorge, escultura de madera policromada, siglo XVIII. 
Pedro Roldán para el retablo mayor del Hospital de la Caridad, en Sevilla entre 1670-1675 o la pintura de Claudio Sánchez Coello que se encuentra en San Lorenzo, El Escorial hecha hacia 1581.

\section{EL LIENZO DE SAN JORGE Y LOS ALACRANES}

La pintura de san Jorge ha estado en la sacristía de la catedral de Durango, por lo menos desde 1822, como así lo refleja el inventario de este año. Se trata de un lienzo que representa al santo justo cuando está a punto de clavar su lanza en el gran hocico de la bestia que yace debajo del hermoso caballo blanco. El santo lleva puesta una armadura que comúnmente es conocida como de placas y que empezaron a utilizarse por lo menos desde el siglo XIV. Asimismo, se aprecia su yelmo con un penacho compuesto por tres plumas de diferentes colores: azul, blanco y rojo. Se observa que el santo tiene un buen dibujo anatómico. Lleva una gran capa roja que envuelve su pecho, lo que parece indicar que la escena transcurre en medio de potentes vientos que provocan que los extremos de la tela vuelen hacia atrás con gran intensidad. Por su parte, el lomo del caballo está cubierto por una gran tela de color azul con bordes dorados que funge como flanquera y por una sencilla pechera de la cual cuelgan algunos bordones. El paisaje de esta obra es muy interesante debido a que no sigue los patrones medievales, renacentistas o barrocos que incluyen castillos, ciudades o grandes construcciones que delaten la ubicación de la escena. En esta ocasión se aprecia un paisaje genérico, con una línea baja del horizonte que pretende dar una importancia a la figura del santo.

Se puede decir que, tanto el dibujo anatómico presente en el lienzo de san Jorge, como el uso de un horizonte bajo y un paisaje genérico, son elementos que formaron parte de las nuevas concepciones que se desarrollaron en la Nueva España durante las primeras décadas del siglo XVIII. En este sentido, Paula Mues menciona que este proceso se dio desde finales del siglo XVII, cuando se estableció de nueva cuenta el gremio de pintores y doradores, y «comenzó a gestarse una transformación de este arte haca una concepción más moderna, ligada a diferentes características como el colorido, la forma del dibujo, la composición, y la utilización de nuevos modelos de belleza" (Mues, 2008: 260). Sin duda, la pintura de san Jorge que se encuentra en Durango puede relacionarse con estas nuevas propuestas, las cuales perduraron, por lo menos hasta principios de la segunda mitad del siglo XVIII. Además del carácter académico de la pintura, el aspecto lúdico que se ve reflejado en la serenidad del rostro del santo, a pesar de la gran batalla que está librando, hace pensar en una obra hecha hacia $1760-1770$.

Finalmente, en esta pintura hay dos elementos iconográficos significativos: la aparición de una serie de animales ponzoñosos a los pies de la bestia, entre ellos, el alacrán endémico de la región de Durango; y la ausencia de la doncella que rescató san Jorge y que es pieza fundamental en este tipo iconográfico. Recuérdese que respecto al primer punto, Vorágine en su Leyenda dorada nunca hace referencia a los alacranes dentro de la historia de san Jorge.

Para entender mejor la inclusión de los alacranes en este lienzo, primero es necesario puntualizar algunos datos sobre la constante batalla que han tenido los habitantes de Durango contra estos animales. Por ejemplo, a partir de 1785, las Gacetas de México dan noticas referentes a estos arácnidos, los cuales señalan la lucha del Ayuntamiento de Durango por aminorar esta plaga a través campañas para su exterminio. Textualmente, se menciona que "por esta perniciosa abundancia de alacranes que en esta ciudad causa tanto estrago 
su piquete, pues quita la vida a numerosas personas grandes y a todas las que no pasan de doce años». El canónigo magistral de la catedral de Durango, José Díaz Alcántara (1751) decía que la vulnerabilidad de los menores ante estas picaduras era evidente, pero, el dolor de perder un familiar por este hecho era más grave. Textualmente señala que, «exprimían [los alacranes] el llanto de las madres, que apenas alhogaban en la cuna a sus pequeñuelos, quando los lloraban en el túmulo».

Posteriormente, en años del México independiente, en la ciudad de Durango, según las noticias publicadas nuevamente en la Gaceta de México, se habían llegado a matar entre el 1 de abril hasta el 31 de mayo del año de 1840 más de 1930 alacranes, los cuales, por cada docena que se entregaban al síndico, se pagaba medio real, lo que sin duda incentivó de manera paralela el oficio de alacraneros, el cual continua hasta la actualidad. A mediados del siglo XIX, José Agustín Escudero (1849) mencionó que los alacranes eran «tan venenosos, que sus picaduras matan a los niños, y a veces también a las personas de una edad madura»" y aclaró que el único remedio para las personas de escasos recursos era beber aguardiente hasta embriagar. Además, recalcó que "por fortuna, no se reproduce este insecto en tan corto tiempo, ni en el número considerable que se cree fuera del país, a causa de las exageraciones con que se habla de esta plaga" (p. 36). Aparte de esta embriaguez para combatir los efectos producidos por el veneno del alacrán, en el Archivo Histórico del Arzobispado de Durango, se encontró un documento que explica un remedio utilizado durante el siglo XVIII, el cual se utilizaba como cura: se trataba de la sangre de Drago, (una resina brillante roja que se obtiene de varias plantas) que se utilizaba también como tintura, incienso y barniz. ${ }^{6}$ Otro de los remedios utilizados, según los informes de Juan Francisco Arce, presbítero de la villa de Nombre de Dios, muy cercana a la ciudad de Durango, era «ajo untado y peladillas de correhuela desechas en agua», además de "agua resacada de alambique de excremento humano llamada contrayerba o yerba sin raíz» (Vallebueno, 2014: 562). Este remedio persistió hasta el siglo XX antes de que se encontrara un antídoto capaz de hacer frente a este veneno.

Hacia comienzos del siglo XX, Adolfo Dollero (1911), tras su paso por la ciudad de Durango, informaba que morían entre 35 y 40 niños de 7 años de edad al año por esta razón (p. 260). Fue hasta septiembre de 1931 durante la segunda convención médica llevada a cabo en Torreón, Coahuila, cuando Carlos León de la Peña e Isauro Venzor Fuedesi presentaron un estudio que resultó en un suero contra el veneno de estos animales.

Dentro del Cristianismo, los animales ponzoñosos han sido parte de una tradición que los representa como elementos malignos, los cuales, como menciona Fillipo Picinelli (1999) se habían convertido en «uno de los territorios mayormente connotados o detractados en la iconografía y el imaginario popular" y una característica compartida por estos animales era la de tener «una función amenazante y destructiva con su inyección ponzoñosa» (pp. 9-42). También, creía que todo lo que había en la naturaleza podía ser leído como un gran libro simbólico, es decir, que todo estaba cifrado y sólo había que entenderlo. Mencionó que había once criaturas que mantenían una lucha traicionera contra la conservación de la vida del hombre a través de sus piquetes y mordeduras y, sobre todo del veneno que inyectan al ser humano (sean animales naturalistas, híbridos o fabulosos). Por supuesto, el escorpión y el dragón fueron incluidos en esta categoría de seres malignos. Cuadriello (1999), en la reedición del libro de Picinelli, menciona que algunos de estos animales fueron vistos por el

6. Archivo Histórico del Arzobispado de Durango, Actas Capitulares, libro 10, 4 de enero de 1769. En adelante AHAD.

IMAGO, NÚM. 10, 2018, 125-142 
hombre barroco como "empresa salvífica» debido a que guiaban a los creyentes al encuentro con su creador. Es decir, estos predicadores mudos (los animales ponzoñosos) picarían al hombre para propiciar su conversión. Estas concepciones, dice el mismo autor «tienen sus raíces en la conciencia del vulgo desde la Edad Media y fue justamente a partir de los años después de Trento el momento de resignificarlas o alegorizarlas de frente a la nueva amenaza doctrinaria de esos tiempos: el hereje, el cismático, el impío» (pp. 9 - 42).

El tipo iconográfico que más se conoce de san Jorge se debe a la publicación del obispo dominico Jacopo da Varazze, quien hizo famosa su historia tras la publicación de su hagiografía escrita hacia 1260. Este autor menciona que san Jorge fue oriundo de Capadocia y un soldado con una gran carrera militar que le permitió conquistar Palestina. Tras haberse convertido al cristianismo y predicarlo, san Jorge encontró pronto el martirio por parte de las autoridades. Entonces, el gobernador Daciano mandó torturarlo de diversas maneras: lo ataron a un potro, le rasgaron las carnes con garfios de hierro, le aplicaron teas encendidas en sus costados, le quemaron las entrañas y le pusieron sal en las heridas, sin embargo, no tuvieron los efectos esperados en el santo y llamaron a un mago para que lo envenenara, pero tampoco resultó efectivo. Luego fue atado a una rueda que giraba llena de espadas de doble filo, pero la rueda, al igual que le sucedió a Catalina de Alejandría, se rompió milagrosamente. Finalmente fue decapitado (Vorágine, 1982: 248-253). Precisamente, en el episodio de la tortura del santo con diferentes venenos fue quizá, el pretexto para jurarlo como patrono de Durango y relacionarlo con el veneno de los alacranes.

Como se señaló anteriormente, otra característica de esta pintura, ubicada en la sacristía de la Catedral, es la ausencia de la doncella, la cual es un elemento básico e imprescindible para la representación del santo. Se dice que estando en alguna ocasión por Silca, en la provincia de Libia, se dio cuenta de que en un enorme lago había un dragón que acechaba a sus pobladores. Vorágine (1982) decía que el olor del animal se caracterizaba por ser pestífero, que el hedor que despedía llegaba hasta los muros de la ciudad. Cada día se arrojaban dos ovejas para que se alimentase la bestia y no los comiese a ellos. Sin embargo, en algún momento tuvieron que sacrificar personas al azar y cuando en una ocasión el destino tocó a la doncella, hija del Rey. Cuando se dirigían hacia el lago a cumplir este designio, se encontraron a san Jorge y mientras sostenían palabras, el dragón salió del lago y se acercó a ellos. Entonces, el santo con toda valentía subió a su caballo y hundió su espada y lo hirió. Luego, lo llevaron hasta las puertas de la ciudad y delante de los habitantes les dijo que Dios lo había traído hasta ese lugar para librarlos de tal bestia y a manera de condición, les pidió se bautizaran y convirtieran al Cristianismo para poder matar entonces la bestia (pp. 248 - 253).

\section{EL OBISPO PEDRO ANSELMO SÁNCHEZ DE TAGLE Y SU RELACIÓN CON SAN JORGE}

Pedro Anselmo Sánchez de Tagle fue natural de la villa de Santillana del arzobispado de Burgos, en la región de Castilla. Fue hijo de Andrés Sánchez de Tagle Bustamante y de Josefa de Valdivieso Barreda y miembro de la tercera generación de una familia de montañeses que llegaron a la Nueva España e influyeron de manera importante en los ámbitos más importantes de la estructura gubernamental por lo menos desde 1724 (Gómez, 2007: 277316). Para 1729 pasó al virreinato como inquisidor y posteriormente obtuvo el decanato del Santo Tribunal. Fue obispo de la catedral de Durango desde 1747 hasta 1758. Se encargó 
de secularizar veintidós misiones jesuitas y continuó con la fábrica material de la catedral. Participó en dos proclamaciones religiosas: la jura de san Jorge que él mismo impulsó para 1749 y la del patronato de la Virgen de Guadalupe, ocurrida el 18 de octubre de 1757. Recuérdese que tres años atrás había sido proclamada por el papa. Posteriormente, fue cabeza de la mitra de Valladolid, donde su mecenazgo, al igual que en Durango, fue evidente en asuntos espirituales y materiales. De manera paralela, hacia 1767, este prelado no olvidó su tierra de origen y mandó dinero para terminar la nueva portada de la iglesia de la colegiata de Santillana (Gómez, 2007: 277-316).

Históricamente, el obispo Pedro Anselmo Sánchez de Tagle, quien estuvo al frente de la mitra de Durango (1747 - 1758), es a quien se le responsabiliza haber encargado o traído el cuadro de san Jorge, tras haber sido el principal promotor de su patronazgo sobre la ciudad contra los animales ponzoñosos [fig. 3]. Sin embargo, esto no es del todo claro, como se verá al final de este trabajo debido a la ausencia de documentos que así lo señalen. Lo que es indudable es la relación del obispo y toda su familia con el santo de Capadocia, quienes hicieron uso y demostración pública de su escudo heráldico, mismo que contiene la figura de san Jorge.

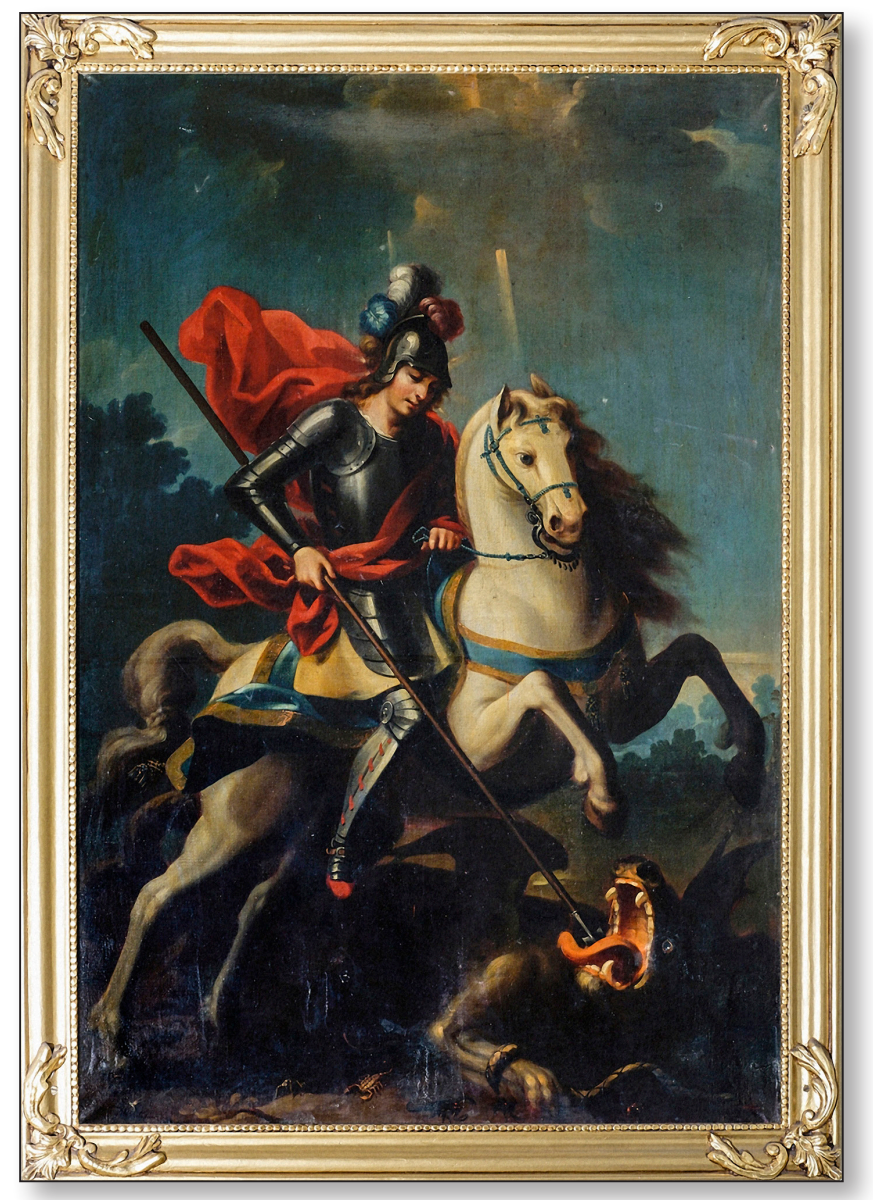

Fig. 3. Anónimo, San Jorge, óleo sobre tela, siglo XVIII. 
El recurso heráldico tiene su origen desde el medievo y tuvo como finalidad que los integrantes de la sociedad feudal se identificaran y sobresalieran del resto con los linajes. En la Nueva España también se incluyeron los diversos escudos en los retratos que se mandaron pintar los diversos funcionarios de la estructura virreinal, tanto civiles como eclesiásticos. A decir de Jaime Cuadriello (2013), el retrato fue el medio idóneo para que una persona pudiera sobrevivir a la posteridad. Es decir, a la inevitable muerte física (p. 155).

En el retrato del obispo Tagle, ubicado en la catedral de Durango y autoría de José de Ibarra, tiene un escudo de plata, con un hombre armado a caballo, quien con una lanza hiere a una serpiente gigante, la cual tiene secuestrada a una doncella. Todo al natural y terrazado de sinople. Bordura de plata con la leyenda Tagle se llamó el que la sierpe mató $i$ con la infanta cassó. En la parte superior tiene una Inmaculada Concepción de pequeñas dimensiones flanqueada por una espada de un lado y un ramo de flores [fig. 4]. Algo destacable, es que este remate inmaculista no lo lleva el escudo del retrato de este obispo que se encuentra en la Catedral de Valladolid (Morelia, Michoacán). Tampoco los escudos de sus parientes el Marqués de Altamira Pedro Sánchez de Tagle (tío del obispo) y Francisco Antonio Sánchez de Tagle (ca. 1760) llevan esta imagen concepcionista. Esto significa que Pedro Anselmo utilizó su heráldica con cierta discrecionalidad de acuerdo a sus intereses.

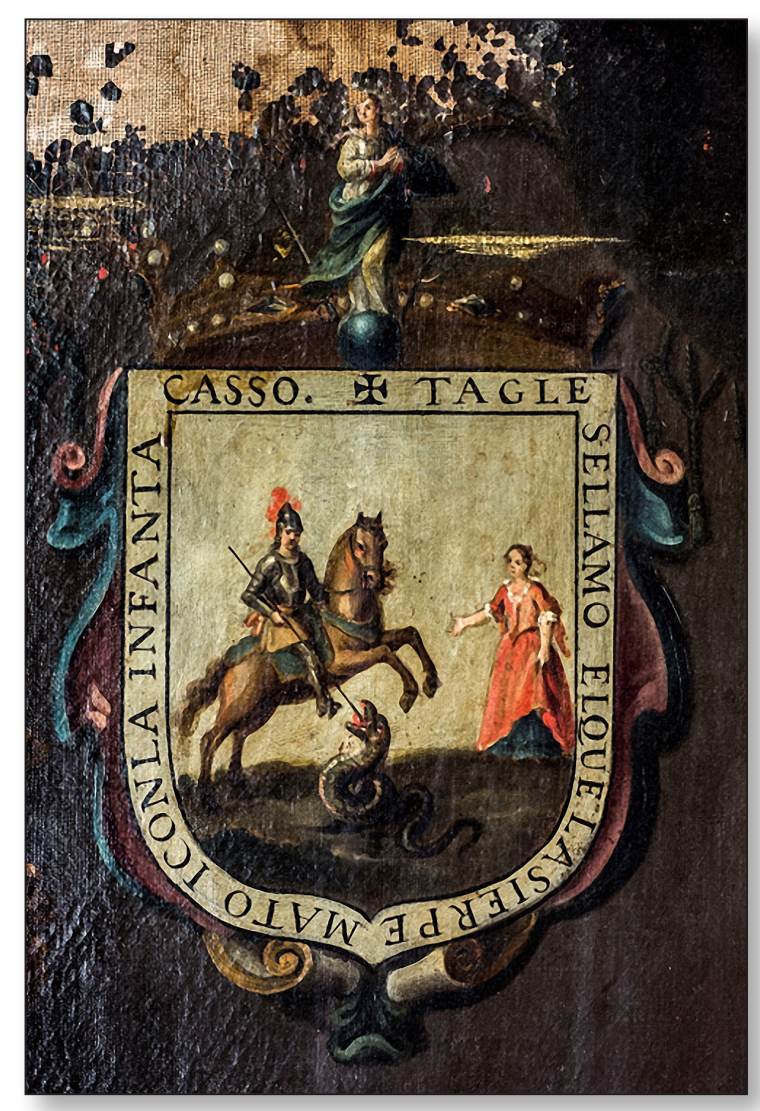

Fig. 4. José de Ibarra, Escudo de San Jorge en el retrato del obispo Pedro Anselmo Sánchez de Tagle, óleo sobre tela, ca. 1754. 
Desde el medievo, los ascendientes del obispo Tagle siempre se vincularon con la estirpe de san Jorge, así lo describen los diversos panegíricos publicados en España. Por ejemplo, fray Manuel de Espinoza menciona el honor de pertenecer a esta estirpe como «aquellos nobles de Capadocia, que restituyeron por su valor y prudencia, una gran parte del Imperio Romano" (1779). Sin duda, este linaje fue bastante reconocido no solamente en España sino también en la Nueva España.

En Durango, san Jorge ya era conocido desde épocas más tempranas. No precisamente lo dio a conocer el obispo Tagle. Su presencia se remonta a mediados del siglo XVII, cuando el obispo Pedro Barrientos Lomelín dedicó parte de sus recursos a construir la ermita de Guadalupe bajo su propia costa, la cual estaba extramuros de la ciudad. Los inventarios señalan que el obispo donó una cantidad considerable de láminas y lienzos de diversos santos para su ornato, entre ellas, una lámina de este santo guerrero. ${ }^{7}$ Por supuesto, sería aventurado señalar alguna devoción ya consolidada para estos años, pero es innegable su presencia.

Es hasta 1736 cuando hay noticias sobre el culto a san Jorge dentro de la Catedral. ${ }^{8}$ Por ejemplo, las actas de cabildo registran el pago al maestro Carreño "por dar color verde a un colateral» dedicado al santo. ${ }^{9}$ Fue hasta 1749 , dos años después de la llegada del obispo Sánchez de Tagle a la mitra, cuando se formalizó junto con el Cabildo catedralicio su juramento como patrono de la ciudad contra los alacranes y demás animales ponzoñosos. Los informes señalan que esto fue posible «según y como particularmente lo avía tratado [el obispo] con los señores capitulares de este cavildo». ${ }^{10}$ El 28 de febrero, el Cabildo Eclesiástico, el Civil, además de los testigos, el arcediano Salvador Becerra Zárate, el Chantre Bernardo Joaquín de Mata del Cabildo Eclesiástico, Antonio García de Arriba, alcalde ordinario y Joaquín Sánchez de Bustamante, segundo comisario del civil, acordaron celebrar anualmente su fiesta el 23 de abril con vísperas, música, sermón y procesión.

Es claro que este acontecimiento no pudo haberse realizado sin antes haber contado con su capilla y altar. Como se mencionó antes, por lo menos desde 1736 hay un altar dentro de la catedral. Su capilla se terminó hasta 1751 y tuvo un costo total de 1, 182 pesos, 7 tomines, incluyendo los materiales como maderas, enjarre, bastidores para las ventanas y vidrieras. ${ }^{11}$ Es relevante que dentro de estas obras no se señala la existencia de ninguna pintura del santo. Sólo se hace referencia a una escultura que, con seguridad es la que actualmente se venera en su capilla. Según la tradición local, a pesar de que no existe ningún documento, se dice fue hecha por Felipe de Ureña, quien trabajó para la catedral por estos mismos años. Empero, dentro del libro de fábrica del año de 1753, se describe el costo de 549 pesos, 2 reales por algunos objetos que Francisco Antuñano había comprado en la Ciudad de México para la catedral de Durango, entre ellos, "cera del norte, aceites, fuegos, cuerdas para el reloj y forros para un ornamento, y una estatua de san George, una clave de capillas y el flete de todo». ${ }^{12}$ Con esta información se aclara que la escultura no fue hecha por Ureña como supone Miguel Vallebueno (2009: 17).

La jura de san Jorge como patrono secundario de la catedral fue un acontecimiento sin precedentes. Para ello, como se acostumbraba en estos casos, se predicó el sermón correspondiente el 23 de abril de 1749. Éste estuvo a cargo del canónigo magistral José Díaz de

7. AHAD, Inventarios, 1658.

8. AHAD, Actas Capitulares, libro 3. 24 de julio de 1736.

9. AHAD, Actas Capitulares, 20 de abril de 1737.

10. AHAD, Actas Capitulares, libro 5, 20 de enero de 1749.

11. AHAD, Fábrica, expediente suelto, año de 1751.

12. AHAD, Fábrica, libro 2, enero de 1753.

IMAGO, NÚM. 10, 2018, 125-142 
Alcántara. ${ }^{13}$ Este personaje había sido académico honorario de la Real Academia de Lengua Castellana en Madrid, teólogo de la Nunciatura de España, juez comisario, subdelegado del Tribunal de la Santa Cruzada del Reino de la Nueva Vizcaya, juez conservador del seráfico orden de N. P. San Francisco de la Provincia de Zacatecas y examinador oficial del obispado. Los dictaminadores de esta publicación fueron Joseph Zedano y Salazar, quien se encargó de la introducción de esta publicación, así como, el padre jesuita Francisco Xavier Lazcano y Cayetano Antonio de Torres Tuñón. Este último, cura interino del Sagrario de la Catedral Metropolitana. Recuérdese que Tuñón era sobrino de Luis Antonio Torres Quintero de quien heredó la biblioteca catedralicia conocida como Turriana. Tuñón describe este evento de la siguiente manera:

\begin{abstract}
desde que en el parayso quedo jurada perpetua lid entre el primer hombre y la serpiente, ni este deja de explorar todas sus artes y astucias en poner assechanzas a los hombres, ni los hombres pueden mirar sin horror á la maligna authora de su desgracia, y primaria causante de su riña. Y en la ciudad de Durango que fue en los tiempos pasados un theatro lastimoso en que le han presentado muchos infelices actos de aquella melancólica tragedia, los alacranes y otras especies de sabandijas e insectos venenosos exprimían, contra tanta plaga venenosa, era necesario un gran patrocinio, ya San Jorge salvo a los israelitas de ello, y lo hará en Durango (Alcántara, 1751).
\end{abstract}

Joseph Zedano, prebendado de la catedral, señala lo siguiente:

que puedo repito yo, decir de la noble prosapia y esclareada grandeza de V.S. Illma, quanto es tan notorio hallarse encadenado el carmín tan rojo e ilustre de su sangre con los más claros príncipes; y solariegas casas hasta concordar con la Regia Divisa de la sierpe, y tymbres gloriosos de Alburquerque, brotando de este tronco florido de su sangre tantos señores prebendados, tantos inquisidores, tantos báculos, y tantas mitras por lo eclesiástico, tantos regimientos, tantos bastones, tantas varas de alcaldes, coroneles, governadores y thenientes criollos por lo secular que coronan su tronco con bellas ramas, tantos blasones, tantos escudos y tantos singulares títulos (Alcántara, 1751).

El mismo Zedano, en una parte del panegírico pregunta: «¿Y quien no sabe de la heroycidad y virtud de la casa nobilisima de V.S. Illma y de la sangre enlazada con San Jorge?». Además, resalta que no se puede ignorar «la heroycidad y virtud [del santo] al librar a la ciudad de Silena y a la infanta inocente de la sierpe, quando lo tiene á los ojos y a la vista en el escudo de armas de la solariega noble casa de V.S. Ilma». Zedano fue más allá, al referirse a Cadmo, hermano de Europa quien fue raptada por Zeus, hijos de Telefasa y Agénor, que según la mitología griega, la madre e hijos salieron en busca de Europa. Entonces algunos se dispersaron y Cadmo fue guidado por el oráculo y llevado hasta una tierra que fundó como su nación. Cuando quiso dedicar un hecatombe (un sacrificio) en ese lugar, había un dragón que mató algunos seguidores de Cadmo, lo que provocó que matara a la bestia, hecho que enfureció a su dueño Ares. Para esto, Zeus lo calmó y envió a Atenas (Minerva) para que solucionara la situación y le permitió a Cadmo ver el nacimiento de los Spartai, una de las legiones guerreras armadas y valientes. Pero aún Ares le exigía que expiara su culpa y Cadmo accedió a casarse con su hija Harmonía. Por esto el panegirista, aseguró que como Cadmo recibió a Concordia (Harmonía) como esposa, no menos las casas de san Jorge

13. Biblioteca Nacional, Colección La Fragua, rollo 1175, El máximo entre los mayores santos y entre los mártires el non plus ultra San George, México: Imprenta de la viuda de Joseph Bernardo, 1751. 
y Tagle, que in facie ecclesiae se vieron desposadas en maridaje y concordia. Aludiendo las virtudes del obispo y equiparándolas con el santo por poner paz y quietud a las ciudades.

Por otro lado, Torres Tuñon destaca el hecho de que a través de la emulación de la insignia de san Jorge, "su familia se ha propagado por todos los dominios de nuestro Catholico Monorcha, que Dios guarde». Igualmente, José Díaz de Alcántara en su sermón menciona lo siguiente respecto al paralelismo del santo y del obispo:

de la misma manera, que por haver vencido al primer hombre la primera de las serpientes, quedó esta prevaleciendo contra todo el resto de los hombres; assi también por la memorable hazaña, que executó el Luchador Sagrado, Invicto Martyr SAN GEORGE (sic) de haver vencido a una Sierpe, logró el venturoso tymbre de ser protector, y escudo contra todo linaje de insectos venenosos (Alcántara, 1751).

Como puede observarse, la relación del obispo Pedro Anselmo Sánchez de Tagle con san Jorge refleja un aspecto fundamental que cualquier prelado tiene como obligación: la protección espiritual de sus súbditos. Es decir, este prelado dio auxilio espiritual y protección militar a su feligresía, tan mermada y decaída por los estragos que causaban los alacranes, a través del impulso de la figura de san Jorge. De alguna manera, también le permitió al obispo perpetuar su nobleza para siempre. Quizá, este caso pudiera interpretarse como un servicio prestado a la Corona como antes ya lo habían hecho sus antepasados en los reinos españoles.

\section{CONCLUSIONES}

Como se vio en este trabajo, la relación del obispo con san Jorge es clara, así como los trabajos realizados para que el santo tuviera su capilla y su imagen escultórica dentro de la catedral de Durango. Asimismo no hay duda del impulso que dio el obispo para que san Jorge diera el auxilio necesario a la población contra la plaga de alacranes. Sin embargo, hay dos cosas que no tienen una explicación contundente: primero, la participación del obispo Sánchez de Tagle en el encargo de la pintura de san Jorge que hoy está en la sacristía; segundo, no es claro si la devoción a este santo guerrero surgió desde el siglo XVIII con el mismo fervor con el que actualmente se manifiesta.

Respecto al primer punto, los inventarios más importantes y conocidos de la catedral del siglo XVIII (1765 y 1790), ${ }^{14}$ se caracterizan por tener un registro muy puntual y detallado de cada objeto registrado, sobre todo los metálicos, Sin embargo, no mencionan la existencia de ningún cuadro de san Jorge. Es hasta 1822 cuando se registran dos lienzos, y no solo uno, mismos que estaban colgados en la sacristía de la catedral. ${ }^{15}$ Este dato genera una serie de cuestionamientos como ¿dónde estaban estos cuadros antes? ¿estuvieron en algún salón privado? ¿cuándo se perdió el otro lienzo? ¿ambos cuadros fueron hechos por el mismo pintor?

Lamentablemente, hasta hace pocas décadas, aún persistían los calificativos negativos que hizo Manuel Toussaint hacia la producción pictórica de la segunda mitad del siglo XVIII (1982). Afortunadamente, las investigaciones actuales evidencian que la pintura de este

14. AHAD, Inventarios, año de 1765 y año de 1790.

15. AHAD, Inventarios, año de 1822.

IMAGO, NÚM. 10, 2018, 125-142 
periodo refleja nuevas inquietudes por parte de los pintores y una nueva concepción de sí mismos. En este contexto, Miguel Cabrera (ca. 1695 - 1768) pudo haber sido el ejecutor de este cuadro o alguien cercano a él. Así, Cabrera o el artista que haya pintado este lienzo tuvo la oportunidad de hacer una reinterpretación del tema, de acuerdo al contexto novohispano y sus intereses. Esta oportunidad de manipular un tema no la tuvo cualquiera.

Finalmente, con base en los datos recabados hasta ahora sobre la devoción hacia san Jorge, se puede decir que no nació con gran intensidad desde 1749, sino que se trata de un fenómeno más reciente. Por ejemplo, desde 1780, tanto la Gaceta de México como el Diario de México, hablan del peligro que representaban los alacranes para la población de Durango. Sin embargo, no señalan ninguna referencia directa con san Jorge y su auxilio contra esta plaga. Asimismo, los autores que escribieron sobre Durango en el siglo XIX no hicieron referencia alguna hacia este santo como protector contra los alacranes. Claro, se entiende que estaban inmersos en ideas más científicas que los alejaban de este tipo de demostraciones religiosas. Una devoción tan arraigada como se supone pudo haber sido la de san Jorge, no hubiera pasado desapercibida para cualquiera. Posteriormente, el historiador del arte Francisco de la Maza visitó Durango en 1947 hizo una serie de comentarios sobre el arte depositado en la catedral. Respecto a san Jorge mencionó que su patronazgo lo impulsó el obispo Sánchez de Tagle «aunque me temo que con muy poco éxito» (1948: 21). Es decir, estas palabras insinúan que su devoción no estaba tan arraigada en la población. Incluso las noticias de los periódicos locales no hacen mención de ello por lo menos hasta 1960. Actualmente, esta información contrasta con aquellas largas filas que se forman tan sólo para entrar a la catedral, ver la escultura del santo, tocarla y pedirle su protección contra los alacranes. Para ello, se utiliza la siguiente frase: «san Jorge bendito amarra a tus animalitos con un cordoncito bendito para que no nos piquen ni a mí ni a mis hermanitos». 


\section{BIBLIOGRAFÍA}

BÁez Macías, E. [1979]. El arcángel san Miguel, México, Universidad Nacional Autónoma de México.

Borromeo, F. [1624]. De pittura sacra. Recuperado en http://www.storiadimilano.it/Arte/ FBORROMEO_PITTURA/FedericoBorromeo.htm

Castorena y Ursúa, J. I. M. [1944]. Gaceta de México. Tomo 1 - 3, México, Talleres del impresor de estampilla y valores de la Secretaria de Hacienda y Crédito Público.

CuAdriello, J. [2013]. «Emblema heroico y sermón fúnebre: el retrato póstumo del capitán Manuel Fernández Fiallo de Boralla», en Jaime CuAdriello (ed.), Ciclos pictóricos de Antequera - Oaxaca. Siglos XVII y XVIII. Mito, santidad e identidad, México, Fundación Alfredo Harp Helú/Instituto de Investigaciones Estéticas, 155 - 194).

Díaz de Alcántara, José. [1751]. El máximo entre los mayores santos y entre los mártires el non plus ultra San George, México, Imprenta de la viuda de Joseph Bernardo.

Dollero, A. [1911]. México al día (impresiones y notas de viaje), París, Imprenta de la Viuda de Bouret.

Escudero, J. A. [1849]. Noticias estadísticas del estado de Durango, México, Tipografía de R. Rafael.

Espinoza, M. [1779]. Oración panegírica de San Jorge Martyr, Zaragoza, en la imprenta de Francisco Moreno, Biblioteca General Universitaria de Zaragoza. Consultada en http://www. aragonesasi.com/sanjorge/oracionpanegirica.php

Gómez Martínez, J. (2007). «La época heroica de los Sánchez de Tagle. La forja de un mayorazgo indiano", en Luis SAzATornil (ed.), Arte y Mecenazgo indiano del Cantábrico al Caribe, Asturias, Trea, $277-316$.

GonzÁlez Estévez, E. (2004). "El retrato ecuestre a lo divino: santos y ángeles a caballo», en RAMÓn MARía SERRERa (Coord.) Nobleza y retrato ecuestre en el arte, Sevilla, Real Maestranza de caballería de Sevilla, 177 - 232.

Gutiérrez Haces, J. et. al. [1997]. Cristóbal de Villalpando ca. 1649 - 1714, México, Fomento Cultural Banamex.

LiNARES L. (2011) «Saint George contre les maures. Specifites et enjeux des representations plastiques du saint guerrier dans ie royaumme d'Aragon (XV - XVI siècles)» en Barrachina (ed.), Cahiers de la Mediterranee. Guerres et guerriers dans l'iconographie et les arts plastiques, 83, 17-32. Recuperado de https://journals.openedition.org/cdlm/6025

López de Gomara, F. [1943]. Historia de la conquista de México, México, Editorial Robredo.

Madalena, T. [1721]. Plano evangélico de sermones varios correspondientes a los empeños, que pueden tener los oradores, Zaragoza, por los herederos de Manuel Roman, Impressor de la Universidad.

Mayans I SiCAR, G. [1742]. Censura de historias fabulosas, obra póstuma de Nicolás Antonio, caballero de la orden de Santiago, Valencia, por Antonio Bordazár de Artázu, Impressor del S. Oficio.

Maza, F. [1948]. La ciudad de Durango. notas de arte, México, Gramma.

Mues, Paula. [2008]. La libertad del pincel. Los discursos sobre la nobleza de la pintura en Nueva España, México, UIA.

Montaner, M. y Redondo G. [1999]. El señor San Jorge. Patrón de Aragón, Zaragoza, Caja de ahorros de la Inmaculada de Aragón. 
Olivares Torres, E. [2015]. L'ideal d'evangelització guerrera. Iconografia dels cavallers sants, Tesis doctoral, Valencia, Universitat de València.

PicinelLi, F. [1999]. El mundo simbólico: Serpientes y animales venenosos, Zamora, Michoacán, El Colegio de Michoacán.

Ruiz Gomar, R. [1993]. «Los santos y su devoción en la Nueva España» Revista de la Universidad de México. Recuperado de http://www.revistadelauniversidad.unam.mx/ojs_rum/ files/journals/ 1/articles/13900/public/13900-19298-1-PB.pdf

Sayrach I. Fatjó, N. [1996]. El patró sant Jordi. Historia, llegneda, art, Barcelona, Generalitat Catalunya.

Toussaint, M. [1982]. La pintura colonial en México, México, UNAM.

VAllebueno, M. (2014). «El informe de los párrocos del obispado de Durango sobre la condición de los indios en 1813. Un acercamiento a la vida cotidiana de sus habitantes», en Guadalupe Rodríguez (coord.), Historia General de Durango, Durango, Instituto de Investigaciones Históricas, Vol. IV, 562 - 590.

Vallebueno, M. [2009]. La catedral de Durango. Un encuentro con el tiempo, Durango, Instituto Municipal de Arte y Cultura.

Vorágine, S. [1982]. La leyenda dorada, Tomo I, España, Alianza Editorial.: 248-253.

ARCHIVOS 